\title{
Proteksi Sistem Keamanan Kendaraan Mobil Menggunakan RFID Berbasis MCU ATMEGA 328
}

\author{
Ganjar Turesna \\ Fakultas Teknik, Program Studi Teknik Elektro \\ Universitas Langlangbuana \\ Jl. Karapitan 116, Bandung \\ gturesna@gmail.com
}

\author{
Wahyu Purnama Sari \\ Fakultas Teknik, Program Studi Informatika \\ Universitas Langlangbuana \\ Jl. Karapitan 116, Bandung \\ wahyu.purnama@unla.ac.id
}

\begin{abstract}
Abstrak - Sistem proteksi atau keamanan saat ini sudah menjadi kebutuhan yang sangat penting bagi mereka yang mempunyai kendaraan mobil. Ini disebabkan tingkat pencurian kendaraan bermotor di negara kita termasuk pada level yang tinggi. Data ini dapat kita peroleh baik pada berita media masa atau media elektronik. Bagi masyarakat yang sudah maju mobil adalah barang yang berharga yang sangat penting untuk melakukan aktivitas rutin sehari-hari, seolah menjadi pengganti kaki untuk mengantarkan orang tersebut ke tempat kerja atau ke tempat lainnya. Jadi kendaraan mobil ini sangat perlu di proteksi terhadap proses pencurian, oleh sebab itu perlu adanya sistem proteksi yang lebih baru untuk mengamankan mobil tersebut dari pencuri. Memang di pasaran telah tersedia alat pengaman untuk mobil diantaranya sistem alarm, atau sistem pengunci dan pembuka pintu mobil menggunakan remote control dengan sistem radio frekuensi/RF. Tetapi menurut infomasi sistem pengaman ini sudah bisa di jinakan oleh beberapa pencuri yang cerdik, sehingga tetap mobil ini berhasil di curi. Ternyata pencuri sudah terlebih dahulu mempelajari titik kelemahan dari sistem pengamanan yang sudah ada. Oleh sebab itu alangkah baiknya ada sistem pengamanan baru untuk kendaraan mobil misalnya menggunakan sistem RFID-eKTP sehingga diharapkan adateknik pengamanan lebih jauh kendaraan mobil mereka dari tangan pencuri. Selanjutnyadengan adanya sistem pengamanan kendaraan mobil dengan RFID-eKTP maka diharapkan adanya suatu proses aplikasi dari teori ke praktek dalam kehidupan di masyarakat dan diharapkan dapat bermanfaat bagi mereka yang memiliki kendaraan jenis mobil.
\end{abstract}

Kata kunci - RFID, eKTP, ATMEGA328, Selenoid, dan Relay

\section{PENDAHULUAN}

\subsection{Latar Belakang}

Tingkat kehidupan sosial masyarakat Indonesia terus meningkat sehingga daya beli semakin meningkat pula. Indikator ini dapat kita baca pada indek penjualan kendaraan bermotor yang terus meningkat setiap bulan sampai setiap tahunnya. Ditambah sistem pembayaran dengan proses kredit yang dipermudah oleh badan finansial melalui proses leasing dengan DP yang cukup ringan maka masyarakat kelas menengah sudah bisa mendapatkan sebuah mobil baru.

Gejala banyaknya mobil baru yang beredar di masayarakat kita dapat kita rasakan langsung dengan adanya kemacetan kendaraan di hampir setiap jalanan kota - kota besar. Tetapi seiring dengan bertambahnya jumlah kendaraan bermotor maka berbanding lurus dengan jumlah pencurian kendaraan bermotor tersebut baik jenis sepeda motor maupun jenis mobil. Walaupun kendaraan mobil tersebut sudah dipasang sistem pengaman tetapi tetap saja banyak mobil yang lolos dari proses pencurian.

\subsection{Rumusan Masalah}

Rumusan masalah dari penelitian ini adalah sebagai berikut :

1. Permasalahan yang diangkat dalam penelitian penelitian ini bagaimana dapat perancangan sistem dobel proteksi kendaraan mobil menggunakan RFID berbasis MCU Atmega 328.

2. Bagaimanakah input dari sensor RFID-eKTP terbaca oleh MCU ATMEGA328

3. Bagaimana output MCU ATMEGA328 dapat mengirim data ke output 


\subsection{Hipotesa}

Modul GSM Neoway M590e adalah chip tunggal modul GPRS industri nirkabel dengan data saja. Memiliki layanan berupa SMS, layanan data dan fungsi lainnya. Modul ini banyak digunakan dalam berbagai jenis bidang industri dan komersial. Apabila digabungkan dengan modul elektronika berupa sensor infra red, mikro swith dan modul minimum sistem control Arduino, maka dapat menghasilkan produk elektronika yang berfungsi sebagai sistem alarm pengingat kunci kendaraan bermotor yang tertinggal.

\subsection{Tujuan}

Tujuan dari pembuatan alat ini yaitu membuat sebuah sistem alarm pengingat kunci kendaraan bermotor berbasis arduino dengan modul GSM (Global system for Mobile Communication) .

\section{2. METODE}

\subsection{Perancangan Hardware}

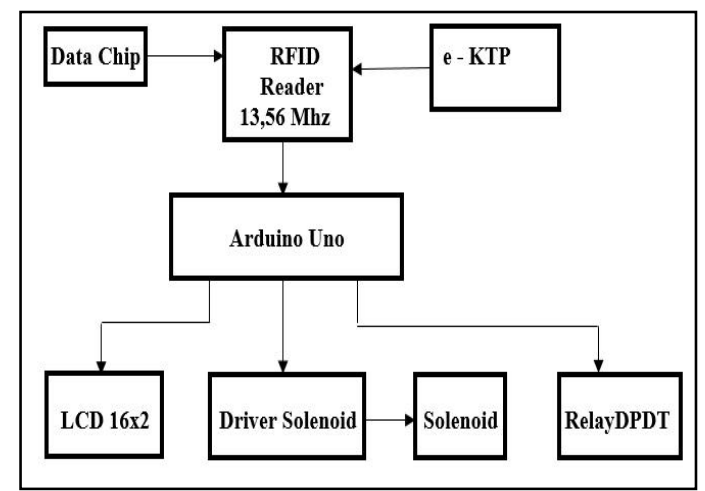

Gambar 1. Blok Diagram Alat

\subsection{Transmitter Chip RFID}

Tag RFID terdiri dari 3 kelompok yaitu :Tag pasif, Tag aktif dan Tag pasif dibantu baterai. Tag aktif memiliki baterai on-board dan secara berkala mengirimkan sinyal IDnya. Sebuah pasif baterai bantu ( battery-assisted passive / BAP ) memiliki baterai kecil di PCB dan diaktifkan bila di dekatkan dengan RFID reader, sebuah tag pasif lebih murah dan lebih kecil karena tidak memiliki baterai.

Untuk memulai operasi dari suatu tag pasif, maka harus diberi daya medan magnit dengan tingkat kekutan daya tiga kali lebih besar dari daya untuk transmisi dari sinyal Tag tersebut sehingga dapat membuat perbedaan dalam gangguan dan paparan radiasi . Tag yang baik hanya dapat di baca dan memiliki nomor seri pabrik dan digunakanpengunci untuk masuk ke dalam database, dimana data objek tertentu dapat ditulis dalam tag oleh sistem pengguna .
Bidang tags dapat diprogram dan ditulis satu kali, tetapi dapat di baca berkali-kali. Suatu Tag yang kosong dapat ditulis oleh programer dengan kode produk elektronik. Sebuah tag tanpa identitas yang melekat selalu mendapat ancaman untuk dimanipulasi.Tag RFID setidaknya mengandung dua bagian, pertama sebuah sirkuit terpadu (integrated circuit / IC) gunanya untuk menyimpan dan memproses informasi, kedua sinyal Radio frekuensi modulasi dan demodulasi, gunanya untuk mengumpulkan energi DC dari sinyal RFID reader juga ada fungsi khusus lainnya. Antena berfungsi untuk menerima dan mentransmisikan sinyal .

Data Informasi pada tag disimpan dalam memori jenis non -volatile. Tag RFID meliputi kabel chip logic atau prosesor data yang dapat diprogram, pengolahan transmisi dan sensor data. RFID reader dapat mentransmisikan sinyal radio yang telah dikodekan untuk mengakses suatu tag. Tag RFID menerima pesan dan kemudian merespon dengan identifikasi dan informasi lainnya.

\subsection{RFID Reader}

Sistem kerja dari RFID reader ini relatif sederhana, RFIDreaderiniakan memancarkan gelombang radio saat card berada di dekat reader, sehingga menimbulkan gaya gerak listrik yang digunakan kartu sebagai catu daya untuk sistem kartu. Selanjutnya card atau kartu dapat mengirimkan serangkaian kode ID ke reader. Apabila ID telah terbaca maka readerakan memberikan perintah kepada mikrokontrol untuk mengaktifkan solenoid yang berfungsi sebagai kendali slot pintu mobil otomatis. Lihat Gambar 2 dibawah iniuntuk jenisRFID card reader buatan pabrik siap pakai, sedangkan Gambar 3 jenis RFID card reader buat eksperimen.

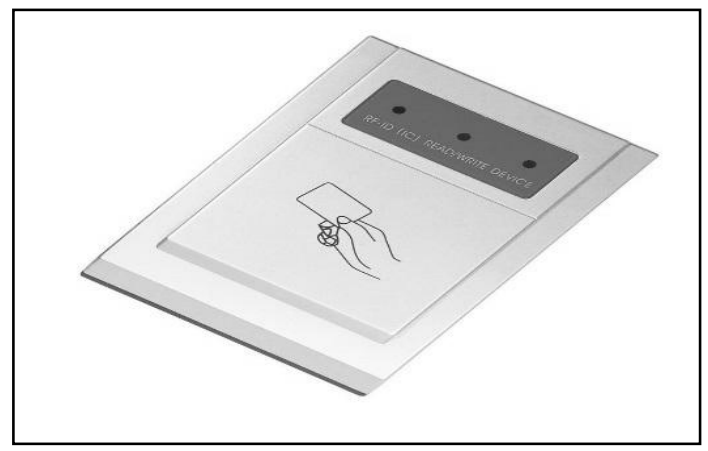

Gambar 2. RFID card reader buatan pabrik 


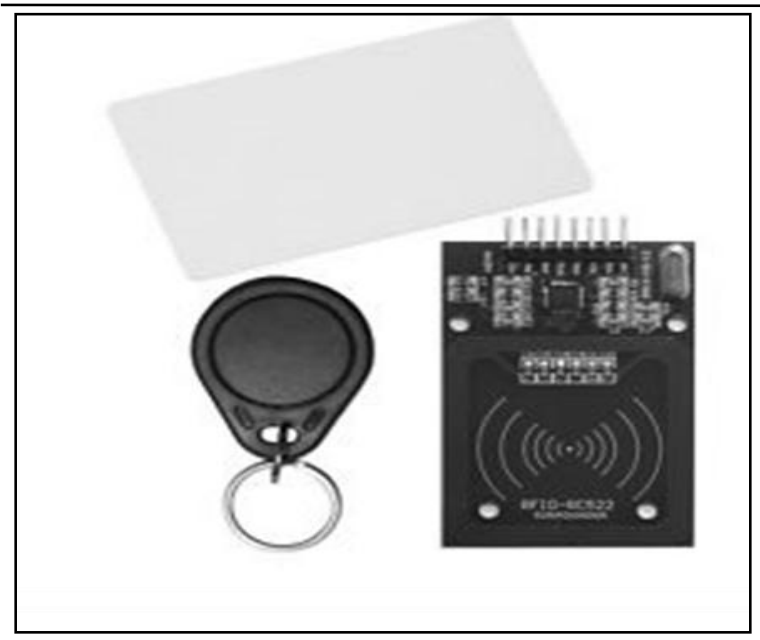

Gambar 3. ChipRFID dan Card reader

Auto-ID bekerja secara otomatis sehingga dapat meningkatkan efisiensi dan mengurangi kesalahan dalam memasukan data. Karena autoID tidak membutuhkan manusia dalam pengoperasiannya, tenaga manusia yang ada dapat difokuskan pada bidang lain. Barcode, smart cards, voice recognition, identifikasi biometricseperti retinal scan, Optical Character Recognition (OCR) dan Radio Frequency Identification (RFID) merupakan teknologi yang menggunakan metoda auto-ID.

Radio Frequency Identification atau yang lebih dikenal sebagai RFID merupakan suatu metoda identifikasi objek yang menggunakan gelombang radio. Proses identifikasi dilakukan oleh RFID readerdan RFID transponder (RFID tag). RFID tag dilekatkan pada suatu benda atau suatu objek yang akan diidentifikasi. Tiap-tiap RFID tag memiliki data angka identifikasi (ID number) yang unik. Sehingga tidak ada RFID tag yang memiliki ID numberyang sama. RFID reader membaca 6ID karakter yang terdapat pada RFID tag sehingga benda atau objek tersebut dapat diidentifikasi.

Secara umum, sistem RFID terdiri dari 4 bagian, yaitu:

a. RFID Tag : dapat berupa stiker, kertasatau plastik dengan beragam ukuran. Didalam setiap tag ini terdapat chip yang mampu menyimpan ID numberdan sejumlah informasi tertentu dan sebuah antena.

b. Antena Berfungsi untuk mentransmikan sinyalfrekuensi radio antara RFID reader dengan RFID tag. Sedangkan dalam RFID tag dan RFIDreader masing-masing memiliki antena internal sendiri karena RFID tag dan RFIDreader merupakan transceiver (transmitter-receiver).

c. RFID reader akan membaca ID number dan informasi yang disimpan oleh RFID tag. RFID readerharus kompatibel dengan RFID tag agar RFID tag dapat dibaca.

d. Software aplikasi Untuk memproses dan menampilkan data yang dimiliki suatu RFID tag yang telah dibaca oleh RFID reader pada sebuah alat seperti misalnya sebuah komputer.

Meski secara umum sistem RFID terdiri dari 4 bagian, pada aplikasinya, jarang digunakan suatu antena tambahan selainantena internal pada masing-masing RFID tag dan RFIDreader.Perpindahan data terjadi yang terjadi ketika sebuah tag didekatkan pada sebuah readerdikenal sebagai coupling. Perbedaan frekuensi yang digunakan oleh RFID tag aktif dengan RFID tag pasif menyebabkan perbedaan metode perpindahan data yang digunakan pada kedua tag tersebut. Perpindahan datapada RFID tag 13 pasif menggunakan metode magnetik (induktive) coupling. Sedangkan RFID tag aktif menggunakan metode backscatter coupling.

Induktive couplingterjadi pada frekuensi rendah. Ketika medan gelombang radio dari reader didekati oleh tag pasif, koil antennayang terdapat pada tag pasif ini akan membentuk suatu medan magnet. Medan magnet ini akan menginduksi suatu tegangan listrik yang memberi tenaga pada tag pasif. Pada saat yang sama akan terjadi suatu tegangan jatuh pada beban tag. Tegangan jatuh ini akan terbaca oleh reader. Perubahan tegangan jatuh ini berlaku sebagai amplitudo modulasi untuk bit data.

Sinyal radio frekuensi dipancarkan oleh reader $(\mathrm{P} 1)$ dan diterima oleh tag dalam porsi kecil. Sinyal radio frekuensi ini akan memicu suatu tegangan yang akan digunakan oleh tag untuk mengaktifkan/menonaktifkan beban untuk melakukan modulasi sinyal data. Gelombang refleksi yang dipancarkan tag dimodulasi dengan gelombang data carrier (P2). Gelombang yang termodulasi ini ditangkap oleh reader.

Tingkat akurasi RFID didefinisikan sebagai tingkat keberhasilan RFID reader melakukan identifikasi sebuah tag yang beradapada area kerjanya. Keberhasilan dari proses identifikasi sangat dipengaruhi oleh beberapa batasan fisik, yaitu:

1. Posisi antena pada RFID reader

2. Karakteristik dari material lingkungan yang mencakup sistem RFID

3. Batasan catu daya

4. Frekuensi kerja sistem RFID

Tingkat akurasi Sistem RFID Pada frekuensi rendah, contohnya pada frekuensi $13,56 \mathrm{MHz}$, komunikasi frekuensi radio antara tag dengan RFID readersangat bergantung pada daya yang diterima tag dari antena yang terhubung dengan RFIDreader. Pada ruang bebas, intensitas dari medan magnet yang diemisikan oleh antena berkurang terhadap jarak, maka terdapat batas 
jarak di mana tag tidak aktif, dan komunikasi frekuensi radio tidak dapat terjadi.Pengurangan ukuran tag akanmengurangi juga batas jarak.

Komunikasi radio berkurang jika medan magnet harus menembus material yang mengurangi daya elektromagnetik, contohnya pada kasus objek dengan bahan logam. Tag RFID tidak akan terdeteksi ketika ditaruh di dalam logam, karena material logam akan meredam fluksmagnet yang melalui tag secara drastis. Orientasi dari tag sangat penting dan dapat menyebabkan medan magnet bervariasi. Jika orientasi tag RFID sejajar dengan arah propagasi energi, maka fluks adalah nol dan komunikasi radio frekuensi tidak akan terjadi walaupun jarak antara antena dan tag sangat dekat.

Pada frekuensi tinggi, perfomansi darisistem RFID sangat bergantung pada lingkungan di mana komunikasi di antara tag dan RFID reader terjadi. Pada jarak tanpa hambatan proses identifikasi dapat terjadi pada jarak 10 meter. Tetapi bila ada hambatan maka jarak ini akan berkurang secara drastis.

Pada frekuensi tinggi, tag RFID bekerja secara aktif dengan daya dari batere. Akurasi dari tag RFID dapat berkurang karena kekurangan daya. Akurasi dari sistem RFID pada umumnya sangat bergantung dari lingkungan di mana sistem RFID dioperasikan.Tantangan desain sistem RFID adalah melakukan desain infrastruktur RFID di antara lingkungan yang kurang bersahabat yang telah dijelaskan sebelumnya.

Dibidang Transportasi RFID digunakan untuk sistem identifikasi yang cepat misalnya untuk untuk menandai bawaan penumpang, dan pengganti tiket sehingga dapat mencegah antrian yang panjang. Bidang Inventory Control system penanganan barang pada proses manufaktur dan distribusi yang efisien dan hemat waktu, dapat disediakan dengan sistem identifikasi yang cepat dan aman.

Hal ini dapat dengan mudah direalisasikan dengan RFID, karena tidak memerlukan kontak langsung, maupun kontakoptik.Dengan tambahan fitur anticollision sejumlah barang dapat diperiksa secara bersamaan.Pada aplikasi ini masalah lingkungan dan kecepatan merupakan peranan yang penting.Pada sistem parkir dengan menggunakan metode RFID, setiap kendaraan masuk hanya membutuhkan waktu selama 10 detik. Karena setiap pemilik kendaraan hanya perlu mendekatkan kartu RFIDnya ke RFID reader, Sehingga secara tidak langsung mengurangi proses antrian.

\subsection{Modul Arduino Uno ${ }^{[1][2]}$}

Fungsi dari mikrokontroller arduino uno adalah pusat proses data sehingga dapat mengendali sistem kerja suatu alat mengikuti program yang telah di upload. Modul arduino Uno memakai IC mikrokontrol Atmega 328, dan memiliki 14 pin digital input/output dimana ada 6 Pinyang dapat digunakansebagai output PWM, 6 input analog, osilator kristall6 MHz, koneksi USB, jack listrik jenis header ICSP, dan ada tombol reset. Lihat Gambar 4 dibawah ini

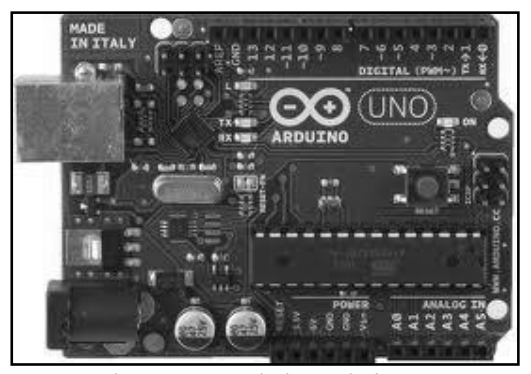

Gambar 4. Modul Arduino UNO

Arduino Uno berbeda dengan semua modul sebelumnya dalam hal itu tidakmenggunakan chip driver FTDI USB - to-serial. Dimana fitur Atmega8U2 diprogramsebagai konverter USB to-serial. Gambar berikut adalah contoh dari modul arduino uno.

\subsection{Sistem Selenoid 12 Volt}

Sistem Solenoid adalah sebuah kumparan atau coil terisolasi atau kawat email pada inti kumparan yang di isi suatu benda berbentuk batang atau bulatan dari besi padat, baja padat, atau bubukbesi.Perangkat semacam ini dapat digunakan sebagai elektromagnet, sebagai inductor dalam sirkuit elektronik, dan miniature antenna penerima nirkabel. Hal ini meningkatkan induktansi dari kumparan dan jauh melampaui induktansiyang diperoleh dengan kumparan ber inti udara dari dimensi yang sama dan jumlah yang sama .

Ketika arus mengalir dalam kumparan, sebagian besar fluks magnet yang dihasilkan ada dalam bahan inti.Beberapa fluks muncul di luar kumparan dekat ujunginti, sejumlah kecil fluks juga muncul di luar coil dan ke samping. Sebuah solenoid berpadu pada silinder, berongga, plastic atau bentuk fenolik bergerak, dengan besi padat atau inti baja.Inti dapat bergerak masuk dan keluar dari kumparan sepanjang sumbu. Kumparan adalah berorientasi vertikal, inti biasanya terletak agak di bawah pusat kumparan. Ketika suatu pulsa listrik diterapkan pada kumparan, maka medan magnet menarik inti pegas atas lihat Gambar 5 dibawah ini. 


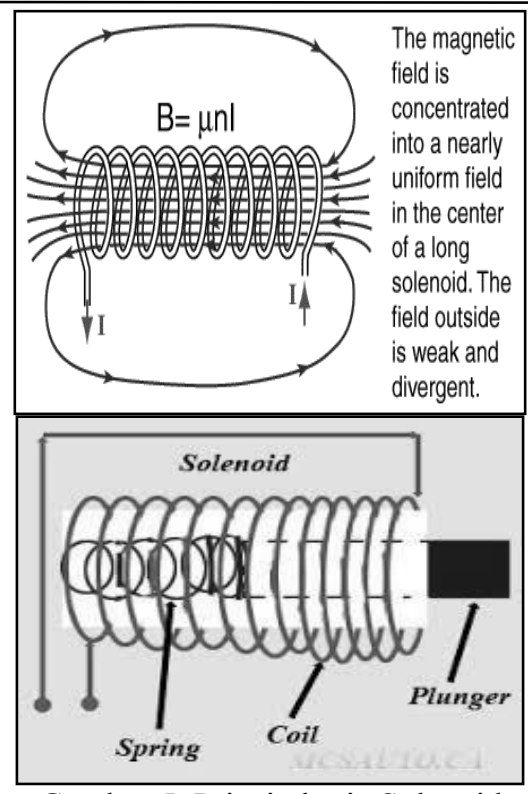

Gambar 5. Prinsip kerja Solenoid

Sebuah kumparan kawat lurus Panjang dapat digunakan untuk menghasilkan medan magnet hampir seragam,mirip dengan sebuah magnet batang. Kumparan tersebut, yang disebut solenoid, dan memiliki sejumlah aplikasi praktis. Bidang dapat diperkuat dengan penambahan inti besi dan menjadi khas dalam elektromagnet. Dalam pernyataan di atas untuk medan magnet $B$ adalah jumlah putaran per satuan panjang, kadangkadang disebut"kepadatan". Ekspresi adalah idealisasi solenoid dengan Panjang tak terbatas, tetapi memerlukan pendekatan yang baik untuk bidang solenoid yang panjang

Diambil contoh sistem kerja solenoid yang dikendalikan oleh suatu transistor NPN. Apabila ada masukan tegangan pada kaki basis misalnya sebesar 5VDC, maka akan ada arus yang mengalir pada basis transistor NPN tersebut, dan mengakibatkan mengalis arus kolektor ke titik emitor /ground melalui kumparan solenoid. Akibatnya pada solenoid akan terjangkit medan magnet yang bisa mendorong besi yang berada di dalam inti kumparan tersebut. Lihat Gambar 6 di bawah ini bentuk real dari solenoid dan Gambar 7 adalah cara pemberian arus langsung ke solenoid oleh transistor NPN.

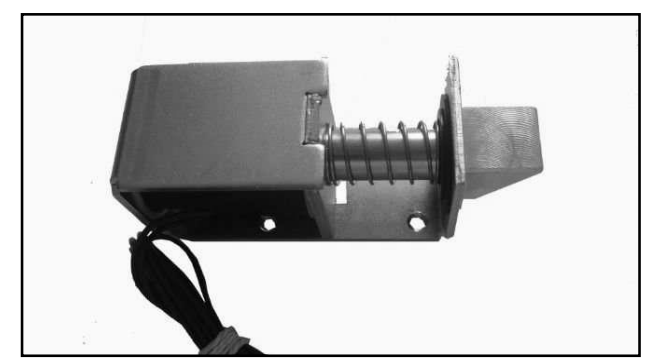

Gambar 6. Bentuk real dari solenoid dorlock

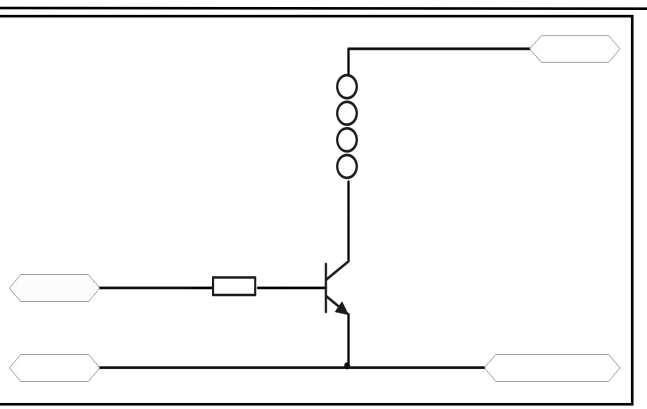

Gambar 7. Rangkaian solenoid dengan transistor NPN

\subsection{Sistem Relay DPDT Coil 12 Volt.}

Relay merupakan rangkaian yang bersifat elektronis sederhana dan tersusun oleh :

1. Saklar

2. Medan elektromagnet (kawat koil)

3. Poros besi

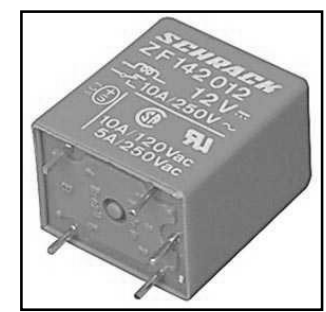

Gambar 8. Salah satu Contohbentuk Relay

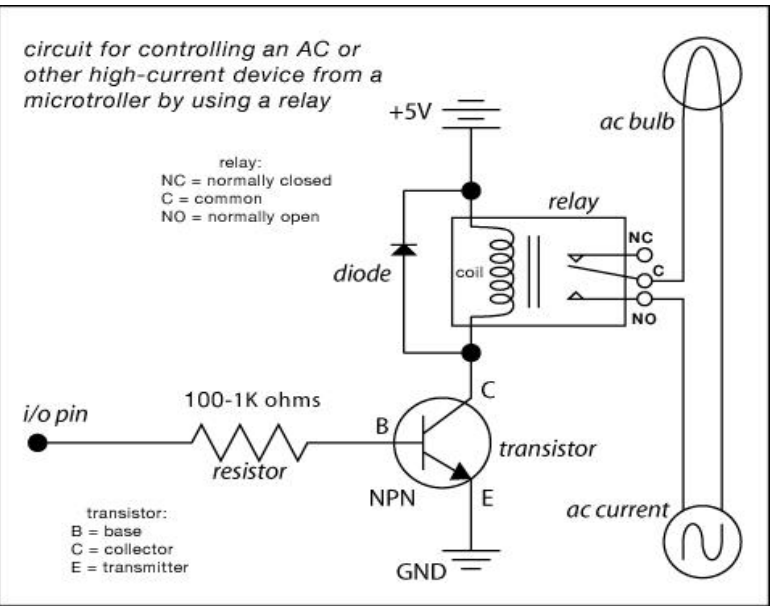

Gambar 9. Contoh pengendalian coil relay oleh Transistor NPN

Cara kerja komponen ini dimulai pada saat mengalirnya arus listrik melalui koil,lalu membangkitkan medan magnet sekitarnya, dan dapat merubah posisi saklaratau plat toggle sebagai kontaktor, dimana kontaktor tersebut dapat mengalirkan arus listrik yang lebih besar tergantung luas dari kontaktornya. Disinilah kelebihan komponen sederhana ini yaitu dengan bentuknya yang minimal bisa menghasilkan arus yang lebih besar. 

yaitu:

Pemakaian relay mempunyai keuntungan

1. Dapat mengontrol sendiri arus serta tegangan listrik yang diinginkan

2. Dapat memaksimalkan besarnya tegangan listrik hingga mencapai batas maksimalnya

3. Dapat menggunakan baik saklar maupun koil lebih dari satu, disesuaikan dengan kebutuhan

Relay adalah keluarga saklar tetapi bekerja dengan sistim elektronik bukan sistim mekanik dimana didalam relay ini kontaktornya ditarik oleh magnet yang berasal dari coil yang disuntik arus listrik. Sistem pengisolasian relay lebih baik dari pada sakelar yang langsung menggunakan transistor, karena kontaktor relay tidak akan ada bocoran arus listrik dan dapat mengalirkan arus listrik lebih besar dibandingkan pakai transistor.

Jika arus listrik masuk ke coil, maka di coil tersebut akan terjangkit magnet. Jika arus listriknya searah (DC), maka kutub utara dan selatan di coil akan tetap, jika diberi arus bolakbalik, maka akan terjangkit magnet dengan kutub utara dan selatan yang berubah-ubah pula.

Adapun hambatan coil relay bervariasi tergantung keperluan daya tarik magnet untuk menarik besarnya plat-plat kontaktor. Biasanya dari puluhan ohm sampai ratusan ohm. Adapun banyaknya jumlah lilitancoil relay akan menentukan besarnya tegangan yang diperlukan. Besarnya kontaktor relay akan menentukan besarnya arus yang dapat dialirkan. Adapun simbol relay dapat dilihat pada Gambar 10 dibawah ini.

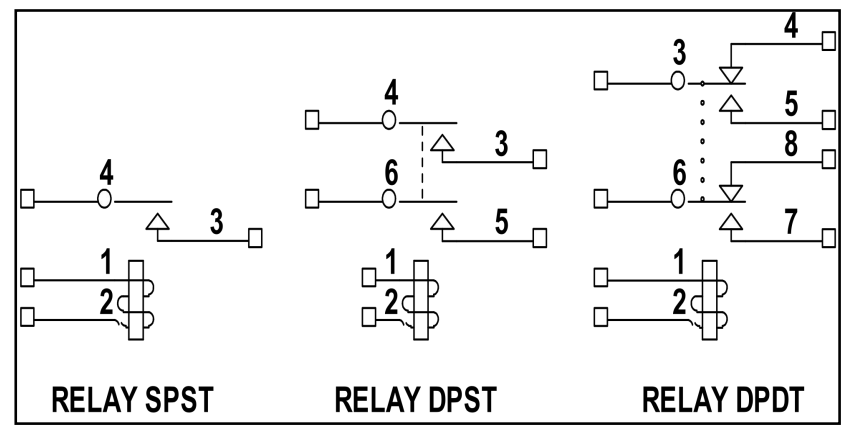

Gambar 10 Berbagai simbol relay dengan bebagai kontaktor nya

\subsection{LCD 16x2}

LCD singkatan dari Liquid Crystal Display berfungsi untuk menampilkan suatu karakter hurup, bilangan dan lain sebagai nya. Karakter yang ditampilkan akan muncul sesuai denganprogram yang telah di upload pada mikrokontroler.Deskripsi dari LCD $16 \times 2$ atau 2 baris dengan 16 kolom dapat dilihat pada Gambar 11.

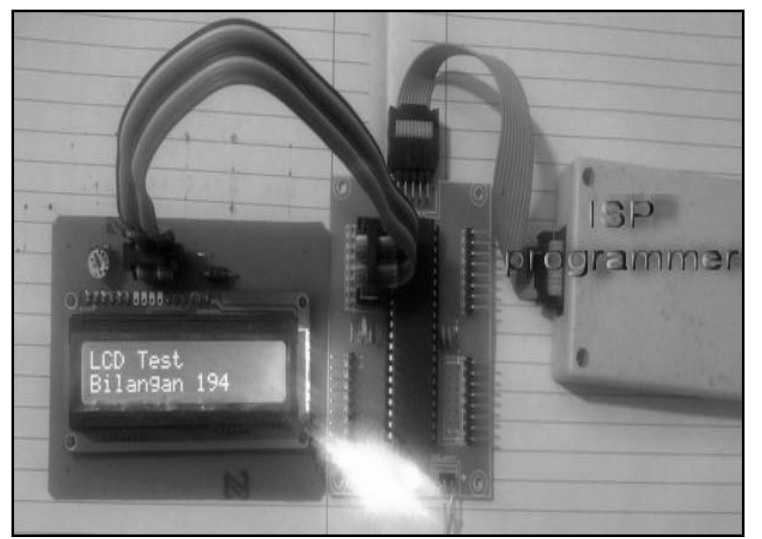

Gambar 11 Contoh fisik dari LCD 16x2 warna biru

Pin data (D0....D4) dapat dihubungkan dengan bus data dari rangkain mikrokontrol dengan lebar data 4 bit, sementara pin kontroler terdiri dari Rs, R/W dan E. Pin Rs (Register select) berfungsi sebagai indikator untuk menetukan jenis data yang masuk, apakah data atau perintah. Logika low menunjukan yang masuk adalah perintah, sementara logika high menunjukan data.

Mikrokontrol akan mengirim suatu karakter atau kata dalam kode ASCII pada input data 8 bit modul LCD, serta mengirim sinyal atau logika high pada pin Rs. Kemudian, mikrokontrol akan mengirim perintah penulisan pada baris ke 1 ataupun baris 2 melalui input data 8 bit dengan memberikan logika high pada pin Rs. Pin R/W berfungsi sebagai instruksi pada LCD, apakah Read atau Write. Ketika R/W diberi logika low berarti penulisan data (write), sedangkan logika high berarti berarti pembacaan data (read). Pin E (Enable) digunakan untuk memegang data, baik masuk atau keluar dari LCD. 


\subsection{Perancangan Software}
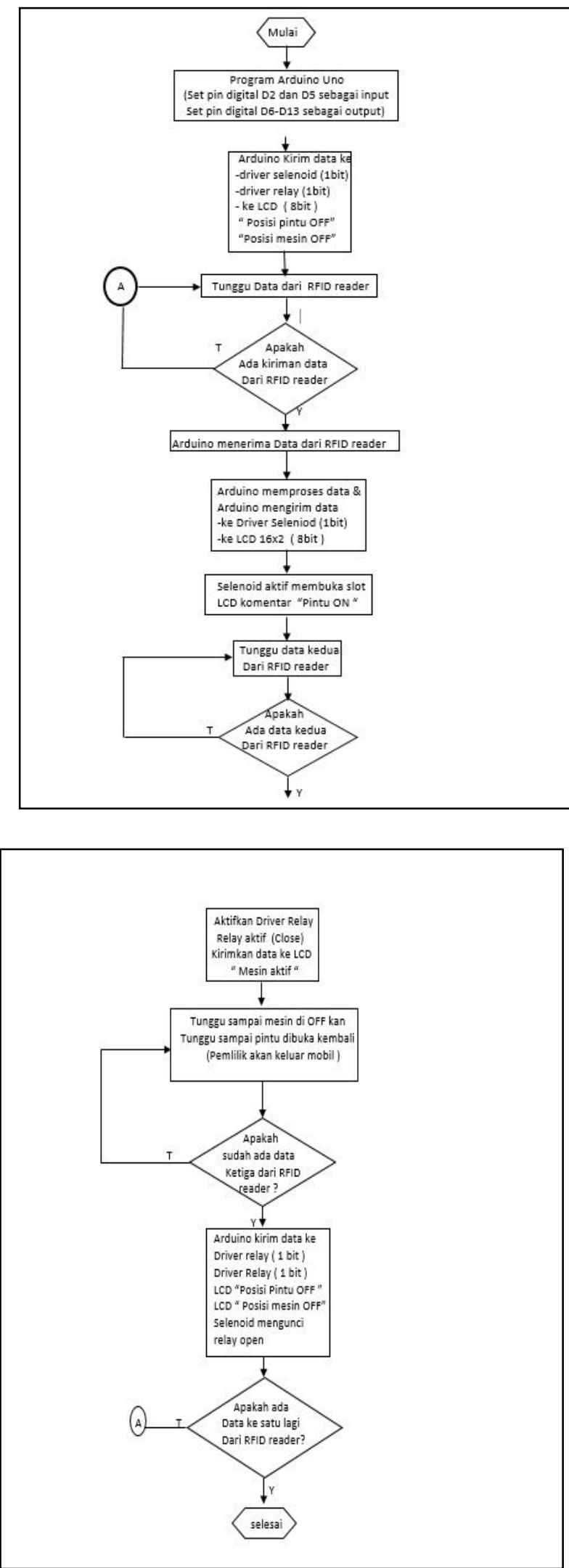

Gambar 12. Flowchart Sistem

\section{HASIL DAN DISKUSI}

\subsection{Perakitan Alat}

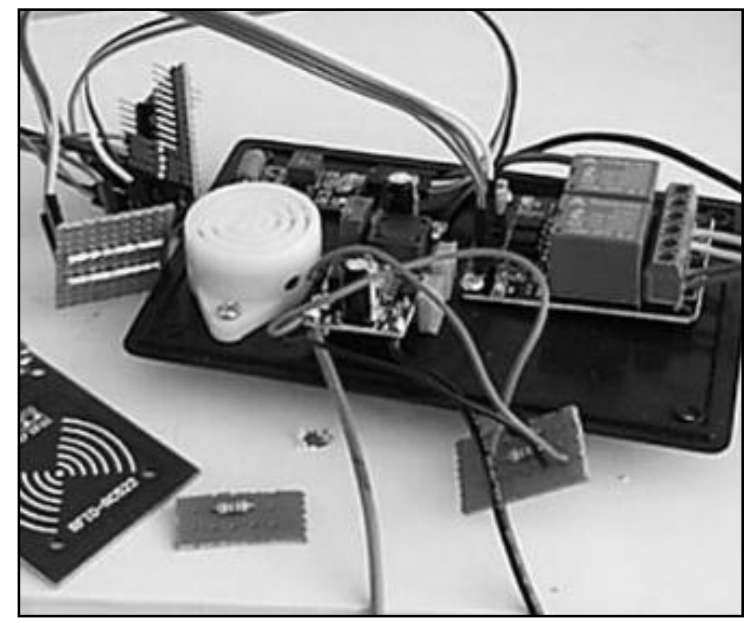

Gambar 13. Perakitan Alat

Semua bagian dari module elektronik dipasang dengan baik agar tidak terjadi konsleting dan pin header diberi lem agar ketika terguncang tidak terlepas yang dapat menimbulkan sistem tidak berjalan, seperti terlihat pada Gambar 14.

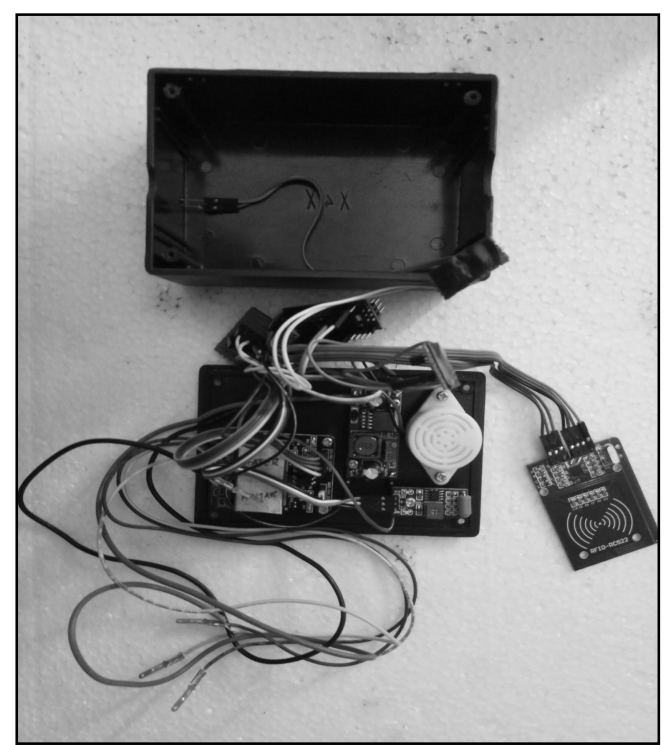

Gambar 14. Perakitan Pada Black Box

Pengujian subsistem RFID dilakukan bersamaan dengan pengujian sistem keseluruhan, namun hanya akan menampilkan khusus hasil pengujian RFID. Pengujian dilakukan dengan menguji dua indikator yaitu pengujian jarak keterbacaan kartu $R F I D$ dan pengujian tanggapan sistem pada kartu $R F I D$ yang berbeda atau dikatakan palsu dan tidak sesuai. 
Hasil pengujian jarak keterbacaan kartu RFID terlihat bahwa pada jarak $0 \mathrm{~cm}$ hingga $2.9 \mathrm{~cm}$ memberikan hasil yang baik, dari 6 kali pengujian pada masing-masing jarak direntang jarak $0 \mathrm{~cm}$ sampai dengan $2.9 \mathrm{~cm}$ dapat terbaca seluruhnya. Pada jarak $3 \mathrm{~cm}$ dari 6 kali pengujian hanya 2 kali sistem dapat membaca kartu RFID. Dengan demikian dapat disimpulkan bahwa module RFID yang digunakan hanya memiliki kemampuan jarak keterbacaan sebesar $0 \mathrm{~cm}$ hingga $2.9 \mathrm{~cm}$ saja.

Pada pengujian tanggapan sistem terhadap kartu RFID lain baik kartu $R F I D$ yang memiliki frekuensi yang berbeda maupun yang sama menunjukan hasil seluruhnya adalah negative, dengan kata lain tidak satupun yang dapat terbaca dan sistem menolak dengan menyalakan alarm sebagai pertanda bahwa sistem keamanan berjalan dengan sangat baik.

\subsection{Pengujian Stepdown}

Pengujian penurun tegangan atau module stepdown perlu dilakukan mengingat sistem keamanan berbasis RFID yang telah dirancang dengan tergantung pada supply yang digunakan. Pengujian ini dilakukan untuk melihat seberapa jauh module ini dapat memberikan kestabilan tegangan terhadap sistem baik ketika Accu dalam keadaan baik maupun dalam keadaan drop atau low. Kestabilan tegangan dan arus yang didapat pada sistem dapat mempengaruhi kinerja dan tingkat daya tahan alat.

\subsection{Pengujian Sensor Getar}

Pengujian sensor getaran dilakukan dengan menguji sensitivitas getaran ketika alat dipasangkan pada motor dengan berbagai simulasi diantaranya ketika motor tersenggol, motor mendapatkan getaran dari laju kendaraan lain, motor berubah posisi dari tersetandar single atau double ke posisi tidak disetandarkan.

Dari hasil pengujian dari berbagai simulasi yang telah dilakukan terhadap respon getaran, semuanya menunjukan hasil yang baik, dimana diberbagai kondisi simulasi yang dilakukan diatas, alat memberikan respon menyalakan alarm kecuali terhadap getaran yang berasal dari getaran laju kendaraan lain.

\subsection{Pengujian Keseluruhan}

Pengujian keseluruhan merupakan pengujian dalam keadaan nyata dan real dilapangan untuk melihat hasil keseluruhan sistem kerja serta kelemahan yang mungkin dimiliki oleh alat yang telah dibuat. Untuk mendapatkan hasil pengujian pada kondisi real, alat harus terpasang pada kendaraan bermotor dan melakukan berbagai simulasi keadaan atau kondisi real.

\section{KESIMPULAN}

Dari hasil penelitian ini dapat disimpulkan jika perancangan alat pengaman kendaraan sepeda motor menggunakan Radio Frequency Identification (RFID) adalah sebagai berikut :

1. Sistem keamanan kendaraan bermotor berbasis Radio Frequency Identification (RFID) dan Arduino Nano berhasil dibuat dan bekerja dengan baik.
2. Dari hasil pengujian juga didapatkan hasil bahwa $R F I D$ hanya dapat membaca kartu yang telah dikenal yang ditanamkan pada logika pemrograman tetapi hanya mampu membaca pada rentang jarak $0-3 \mathrm{~cm}$.

3. Berdasarkan hasil pengamatan dan pengujian yang dilakukan, maka penulis dapat mengambil kesimpulan bahwa kinerja Sistem Pengamanan Kendaraan Mobil ini bekerja dengan cukup baik. Ketika RFID Reader menerima input dari Tag ID dan diteruskan oleh Microcontoller sehingga Microcontroller akan memberikan Output-nya kepada Relay untuk menghidupkan kontak dan starter sehingga kendaraan bermotor akan menyala. Ketika kendaraan mobil menerima getaran, sensor getaran akan diteruskan oleh Microcontroller sehingga Microcontroller akan memberikan Output-nya kepada Light Emitting Diode (LED) dan Buzzer.

\section{UCAPAN TERIMAKASIH}

Terima kasih telah memberi kesempatan untuk meneliti. Penelitian ini dibiayai oleh DRPM dan LLDIKTI4 sesuai dengan Surat Perjanjian Penugasan Penelitian Dosen Pemula dengan Kontrak Penelitian Bulan Maret 2019.

Nomor : 2667/L4/PP/2019

\section{DAFTAR PUSTAKA}

[1] Ibtada M dan Somantri Yoyo. 2015. Module Pelatihan Arduino Nano. Bandung: UPI. p.2

[2] Russell, David. "Introduction to Embedded System Using ANSI C and the Arduino Development Environment", ATmega328P Architecture, 2010, ISSN : 9781608454990.

[3] Saleh M dan Haryanti Munnik, 2017, Rancang Bangun Sistem Keamanan Rumah Menggunakan Relay, Jurnal Teknologi Elektro, Universitas Mercu Buana, Vol.8, hal. 181-183

[4] Srivastava, Lara. 2005. Ubiqitous Network Societies: The Case of Radio Frequency Identification, ITU Workshop On UNS, Geneva

[5] Suhardi Diding, 2014, Prototype Controller Lampu Penerangan LED Independent Bertenaga Surya, Universitas Muhammadiyah Malang, Jurnal Gamma, vol.10, 116-122

[6] Syafruddin, Raden Muhammad dan Fitri, 2012, Perancangan Sistem Kendali Gerak Lengan Robot Pengikut Gerak Lengan Manusia Berbasis Mikrokontroller, Skripsi, Program Sudi Teknik Informatika, STMIK GI MDP, Palembang

[7] Yuwono, Dinata Marta. 2015. Microcontroller itu mudah. Jakarta: PT.Elex Media Permata

[8] http://elektronika-dasar.web.id/pengertian-dankomponen-radio-frequency-identification-rfid/ (Diakses pada 30 Agustus 2018)

[9] https://elektronika64.wordpress.com/2016/08/21/pengerti an-resistor-fungsi-dan-nilai-resistor/ (Diakses 10 Oktober 2018)

[10] http://www.academia.edu/24374962/SENSOR_GETAR (Diakses pada 15 Januari 2018) 